\title{
Abordagem
}

Alberto Carvalho da Silva

\section{Discurso de outorga do título de Professor Emérito da USP*}

\section{"Cabe à Universidade o encargo de dar o exemplo de como deve ser exercida a democracia para que esta se consolide"}

Não é preciso dizer o quanto me sensibiliza e enobrece o título de Professor Emérito da Universidade de São Paulo, outorgado pelo Conselho Universitário, e que recebo hoje das mãos do Magnífico Reitor, prof. Jose Goldemberg.

Também me desvanecem as palavras de carinho do ilustre diretor do Instituto de Ciências Biomédicas, prof. Oswaldo Lopes. Mesmo sabendo que são inspiradas por sua bondade e cortesia, não me furto a confessar que gostei muito de ouvi-las e gostaria ainda mais de merecê-las.

Recebo esta distinção quase 55 anos depois de ter iniciado o curso médico na Faculdade de Medicina, no mesmo ano em que a Universidade de São Paulo foi criada. E penso que a longa convivência que tenho tido com o sistema nacional de ensino superior me credencia para afirmar que esta Universidade $e$ o que de melhor já se fez em ensino e pesquisa, no Pafs.

Faço esta profissão de fé porque o período atual é de definições claras e posiçōes firmes para preservar o que temos de bom. As dificuldades que o País atravessa fazem com que este e outros centros de ensino e pesquisa que têm consciência de sua qualidade e de seu papel no desenvolvimento e na autonomia da Nação evitem, a todo o custo, ceder à pressão dessas dificuldades que têm a particular malícia de destruir mais e mais depressa o que é melhor.

Em mais de meio século de existência, a Universidade de São Paulo já passou por outras fases críticas que puseram à prova a sua vitalidade e a firmeza de suas raízes. Isso não impediu que ela crescesse em número de alunos, em corpo docente, na produção de ciência e de idéias e na amplitude e beleza de seu campus. Este progresso é o fruto do esforço, da dedicação e da clarividência de seus fundadores, liderados por Armando de Salles Oliveira; dos professores-visitantes que aqui vieram formar as primeiras geraçōes na Faculdade de Filosofia, Ciências e Letras; da Fundação Rockefeller, que incentivou o tempo integral na Faculdade de Medicina e apoiou a formação de pesquisadores, primeiro nas ciências médicas e depois em outros campos dả ciência.

* Cerimônia realizada em 9 de novembro de 1988, em São Paulo. 


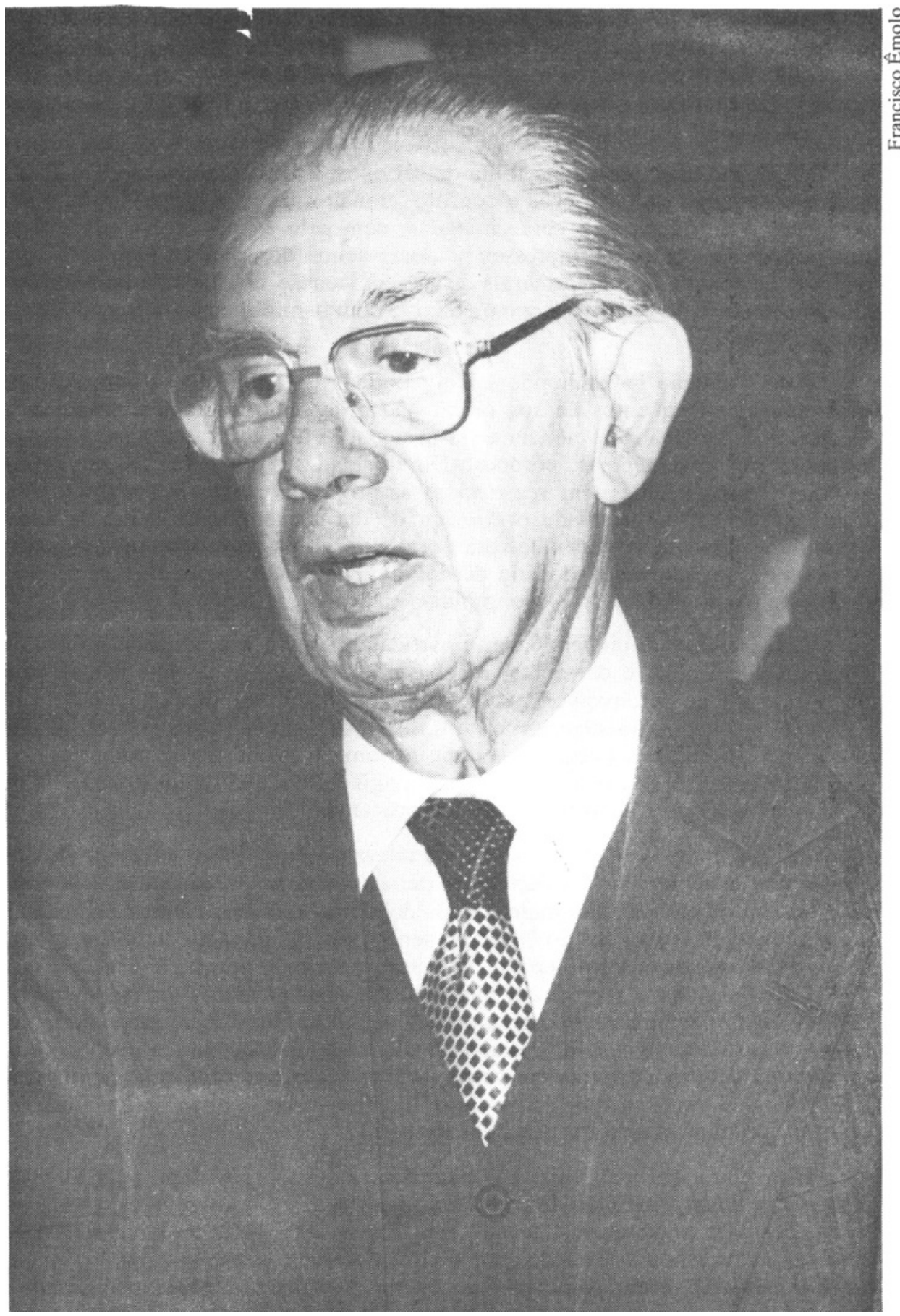

A estes esforços, a Universidade respondeu com iniciativas históricas como a criação dos Fundos Universitários de Pesquisa sob o comando do reitor Jorge Americano em 1942; a instalação da FAPESP, por Carvalho Pinto em 1960, sob a liderança do reitor Ulhôa Cintra; a contribuição para a formação de numerosos outros centros de excelência no estado, e de pesquisadores e docentes para outros centros nacionais e do Exterior. E, por fim, quando na década de $\mathbf{6 0}$ foi introduzida a pós-graduação formal, a Universidade de São Paulo foi, mais uma vez, o principal esteio de uma iniciativa de âmbito nacional a ponto de que, passados trinta anos em que o sistema se consolidou e se expandiu, ela ainda dá conta de mais de um quinto de todos os programas de mestra- 
do e mais de um terço dos de doutorado, além de contribuir com quase a metade dos de melhor nível. E, para confirmar esta liderança, são os seus pesquisadores que absorvem mais da metade dos recursos da FAPESP e que, entre 1985 e 1987, fizeram jus a quase um quinto dos recursos que o FNDCT coloca à disposição de todos os centros de pesquisa do País.

Com este histórico e esta folha de serviços, a Universidade de São Paulo nada tem a temer de incertezas e conflitos transitórios. Sua força interna e sua consciência de missão não serão afetadas, nem pelo espírito corporativista de uns poucos que colocam interesses pessoais acima dos sociais, nem pelas freqüentes demonstraçōes extramurais de incompreensão do que seja uma universidade, como se desenvolve e como convive com os problemas da sociedade em que se insere.

Esta condiçāo ímpar impõe à Universidade de São Paulo a obrigaçăo de fazer revisóes freqüentes de sua orientação e de seus programas, procurando ajustar-se à evolução da ciência e da sociedade. É natural que nestes ajustes surjam fortes divergências, porque a Universidade $\epsilon$, por natureza, um fórum em que todas as idéias têm vez e todas as propostas merecem ser discutidas. Cabe, porém, à Universidade o encargo de dar o exemplo de como deve ser exercida a democracia para que esta possa consolidar-se e desmentir os maus agouros de que as sociedades em desenvolvimento não sabem exercer a liberdade com a continência e o respeito indispensáveis.

Cabe também à universidade, e particularmente à universidade pública, a obrigação de avaliar e dar contas à sociedade do seu desempenho nas atividades essenciais de desenvolver a ciência, a arte e a cultura; de atender à demanda social por educação superior; e de formar profissionais competentes, atualizados e diversificados. Longe de ser um instrumento de censura e controle, essa avaliação constitui um meio idôneo de corrigir falhas, reorientar programas ou mesmo instituiçōes e justificar novos investimentos.

Acompanhando os grandes centros internacionais, a Universidade de São Paulo vem concentrando a maior parte de seus recursos de pesquisa nos temas de fronteira da ciência. Em muitas áreas de ponta os nossos centros comparamse com os mais avançados do Exterior, senão em volume, pelo menos em qualidade. Esta orientação está certa e deve ser preservada porque a ciência é universal. Mas $€$ forçoso reconhecer que, com algumas exceçōes, os cientistas nacionais vêm relegando a um segundo plano a análise dos subprodutos da pobreza em que se debate mais da metade da nossa população. No melanc6lico cortejo desses subprodutos marcham à frente a subnutrição; a elevada mortalidade e morbidade infantil; a repetência e a deserção escolar; a alta criminalidade juvenil; a violência contra a criança e a mulher:

Está claro que não cabe aos cientistas a responsabilidade pela solução desses problemas; mas cabe-lhes analisa-los, identificar e divulgar as suas causas, e desfazer preconceitos de que eles possam estar vinculados a forças de natureza cultural, ou à má índole de adultos ou crianças, ou, em uma visão ainda mais perversa, a traços raciais e genéticos. Ao colocar perante a sociedade e seus governos a origem desses males, os cientistas abrem o campo para o debate público e criam condições que podem contribuir para acelerar a sua solução.

De uma outra perspectiva, as nossas universidades estão, cada vez mais, na obrigação de manter o intercâmbio com a empresa como contribuição para o desenvolvimento industrial e para ajustar os seus programas de treinamento às necessidades e oportunidades do mercado de trabalho. Os países fortemente industrializados, em que de $40 \%$ a $70 \%$ do investimento em ciência e tecnologia vêm do setor privado, estão investindo aceleradamente no desenvolvimento de parques de ciência, pólos técnicos, institutos de transferência tecnológica e outras estrategias para intensificar ainda mais essa cooperação, com apreciáveis

(...) sobram a universidade desafios para novas iniciativas em prol do desenvolvimento da ciência, da cultura, das artes e do bem-estar humano. 
retornos tanto no desenvolvimento científico como na indústria. Nos Estados Unidos, a National Science Foundation déstina parcela representativa de seu orçamento ao desenvolvimento de pequenas empresas baseadas em inovação tecnologica. E, inspirado no sucesso deste empreendimento, o governo norteamericano determinou recentemente que todas as agências federais de financiamento de pesquisa adotem programa semelhante.

Para nos, com uma inđústria que não tem tradição de investir em pesquisa, e às vezes nem sabe como fazê-lo, $€$ tarefa prioritária procurar formas eficazes de estimular esse intercâmbio para dar ao nosso sistema industrial maior capacidade de competir nos mercados internacionais e gerar a riqueza de que o País necessita para alcançar o desenvolvimento com justiça social.

No conjunto, a par da manutençäo regular das atividades tradicionais, sobram à universidade desafios para novas iniciativas em prol do desenvolvimento da ciência, da cultura, das artes e do bem-estar humano. Estar alerta para essas oportunidades e desafios, enfrentá-los com coragem e determinação e defender a instituição universitária por seus méritos intrínsecos, seus objetivos, e seus compromissos com o progresso, são os mandamentos pelos quais a comunidade universitária se rege, orienta as suas reivindicaçōes e alimenta o seu espírito de luta. E, em grande parte, graças a esse esforço e essa consciência de missão da comunidade científica que o investimento nacional em ciência e tecnologia triplicou nos últimos dez anos em relação ao produto interno bruto. Mas é de se lamentar que a soma dos orçamentos de CNPq, CAPES e FNDCT, as três entidades federais incumbidas de financiar pesquisa nas universidades $e$ formação de novos pesquisadores, não tenha aumentado no mesmo ritmo.

Estas distorções não surpreendem nem causam desânimo. Elas são próprias dos países em desenvolvimento em que os recursos são escassos e as decisões nem sempre são coerentes. $O$ que essas distorções de fato comprovam é a necessidade de vigilância e diálogo permanentes para que elas possam ser corrigidas. Essa vigilância e esse diálogo devem ser mantidos pelas lideranças universitárias com energia e perseverança, mas sem agressividade ou presunção de má-fé e sem perder de vista que o desenvolvimento de uma estrutura científica dinâmica e atualizada $\epsilon$ um processo lento e compete com outras prioridades sociais tambem validas. Orgulho-me de dizer que boa parte desta batalha tem sido alimentada pelos docentes da Universidade de São Paulo e que, nas fases em que participei, sempre encontrei por parte deles uma fiel obediência a esta conduta madura e democrática. Manter esta orientação, o amor e o respeito pelo diálogo construtivo e a busca incansável do consenso, são as normas pelas quais devem guiar-se as campanhas em favor da Universidade, para que nunca se questione a justeza e a transparência dos objetivos de seus pleitos.

Magnífico Reitor, ao encerrar estas palavras quero, mais uma vez, agradecer a V.Ma. e ao Conselho Universitário a generosidade de me outorgar este honroso título, colocando-me como par de uma plêiade de homens ilustres.

E, como o mais recente dos professores eméritos, peço aos meus novos colegas autorização para falar em seu nome, assegurando a V.Ma. que nós ainda estamos na luta pela Universidade; que acreditamos que ela continua sendo a fonte principal da ciência, da cultura e das artes; e que estamos sempre dispostos a trabalhar para que ela possa desempenhar com acerto a sua missão de contribuir para que a sociedade seja cada vez mais esclarecida; harmoniosa e justa.

Alberto C. da Silva é Professor Emérito da USP e diretor-presidente do Conselho Técnico e Administrativo da FAPESP. 